\title{
O consumo de tabaco pelos pais e filhos: Um estudo numa escola do interior
}

\author{
alentejano
}

\section{Smoking by parents and children: a study in a school in the interior of Alentejo}

\author{
Jorge Ferreira*, Jorge Bonito**, Cristina Simão* \\ * Agrupamento de Escolas n. ${ }^{\circ} 2$ de Serpa, ${ }^{* *}$ Universidade de Évora, Universidade de Aveiro
}

\begin{abstract}
Resumo
A exposição ao fumo ambiental do tabaco (FAT) representa um risco acrescido para a saúde pública. É nas suas próprias casas que as crianças correm maior risco de exposição ao FAT, em especial quando a mãe ou o pai são fumadores. Este estudo procurou conhecer a prevalência de crianças e jovens de uma escola do interior da região Alentejo expostas ao FAT. Aplicou-se um questionário a uma amostra de 141 alunos. Os resultados revelam que são em menor número os pais que fumam em casa dos alunos mais novos. $\mathrm{O}$ estudo permitiu definir algumas estratégias de abordagem a este fenómeno.

Palavras chave: fumo ambiental do tabaco, crianças, pais fumadores.
\end{abstract}

\section{Abstract}

Exposure to environmental tobacco smoke (ETS) poses an increased risk to public health. It is in their own homes that children are at higher risk of exposure to ETS, especially when the mother or father are smokers. This study sought to know the prevalence of children and young people of a school in the interior of the Alentejo region exposed to ETS. A questionnaire was applied to a sample of 141 students. The results show that fewer parents smoke at home of the younger students. The study allowed to define some strategies to approach this phenomenon.

Keywords: environmental tobacco smoke, children, smoking parents.

\section{Introdução}

Em Portugal, "todos têm direito à proteção da saúde e o dever de a defender e promover" (n. ${ }^{\circ} 1$ do art. 64. ${ }^{\circ}$ da CRP), desenvolvendo práticas de vida saudável (al. b) n. ${ }^{\circ} 2$ do art. $64 .^{\circ}$ da CRP). O Estado português reconhece "à criança o direito a gozar do melhor estado de saúde possível (...) tomando medidas para combater a doença (...) tendo em consideração os perigos e riscos da poluição do ambiente" (art. 24. ${ }^{\circ}$ da Convenção sobre os Direitos da Criança). A exposição ao FAT representa um risco acrescido para a saúde pública. A $U S$ Environmental Protection Agency considera efeitos comprovados o cancro do pulmão, a doença cardiovascular, os sintomas respiratórios e a exacerbação de asma (EPA, 2016). As vias aéreas e o sistema imunitário das crianças estão menos desenvolvidos que nos adultos; por isso, elas tornam-se mais suscetíveis a infeções respiratórias e infeções do ouvido médio. É nas suas próprias casas que correm maior risco de exposição ao fumo em segunda mão, em especial quando a mãe é fumadora, uma vez que é ela que normalmente mais cuida das crianças (Pestana, 2010), sendo preocupante a possibilidade de inversão da tendência para que as mulheres adultas fumadoras, em Portugal, provenham de um meio socioeconómico favorecido (Alves, Kunst \& Perelman, 2015).

Um estudo realizado com uma amostra representativa de 8764 adolescentes portugueses que frequentavam as escolas públicas do ensino regular do $5 .^{\circ}$ ao $12 .^{\circ}$ ano (incluindo as regiões autónomas), no ano letivo de 2008/2009 (Precioso, Samorinha, Macedo \& Antunes, 2012), determinou que a prevalência do consumo de tabaco é superior na região do Alentejo (14,7\%), registando-se a prevalência mais baixa na região do Algarve (4,1\%). Ao contrário de outras regiões, em Lisboa e Vale do Tejo e no Alentejo o consumo regular de tabaco é mais elevado no sexo feminino. O estudo determinou, ainda, que a prevalência de consumidores de tabaco aumenta com a idade em ambos os sexos, sendo que, aos 15 anos de idade, $12,3 \%$ dos rapazes e $8,6 \%$ das raparigas consomem tabaco regularmente. Um outro estudo, ainda com adolescentes portugueses como população de estudo (1900, com idades entre 14 e 17 anos), permitiu estabelecer uma associação entre o estatuto socioeconómico e o tabagismo, com o hábito de fumar regularmente a ser mais provável em alunos com pior desempenho escolar, maior semanada e filhos de pai desempregado (Cristina, Alves \& Perelman, 2015). A restrição do consumo de tabaco em meio escolar parece não ter efeito sobre o hábito de fumar dos estudantes, mas poderá contribuir para o decréscimo da exposição dos alunos ao tabagismo e prevenir a iniciação do comportamento de fumar na escola. Em escolas onde muitos alunos fumem nas suas imediações pode haver um ambiente favorável ao tabagismo (Kuipers, Korte, Soto, Richter, Moor, Rimpela et al., 2015).

Pela possibilidade de articular os sectores da saúde e da educação, de modo a proporcionar uma abordagem pedagógica ativa e não meramente informativa, com o desenvolvimento de competências de decisão, com sentido crítico e responsabilidade, e o desenvolvimento 
da capacidade de resistir às pressões sociais, em particular à pressão dos pares, a escola é um contexto ideal para implementar um programa de prevenção do tabagismo (Nunes, 2007). A possibilidade de articulação com as famílias é também uma mais-valia na educação e promoção da saúde ao nível da escola. Os pais e educadores podem ajudar na prevenção do tabagismo, quer abstendo-se de fumar na presença de crianças e jovens quer adotando uma atitude que não seja permissiva e que não facilite o acesso ao tabaco.

Neste contexto, este estudo parte da seguinte questão-pivô: Quais são os hábitos de consumo de tabaco dos adolescentes e dos seus familiares e o grau de exposição ao FAT de crianças na sub-região do Baixo Alentejo? Procurou dar resposta aos seguintes objetivos: a) determinar a prevalência de crianças e jovens fumadores; b) determinar a prevalência de pais fumadores e que o façam no domicílio; c) conhecer as representações dos alunos relativamente ao tabagismo; d) propor medidas de atuação sustentadas nos resultados obtidos.

\section{Metodologia}

A investigação seguiu uma abordagem quantitativa, de natureza transversal e exploratória. O estudo foi desenvolvido num agrupamento de escolas do município de Serpa, cidade raiana do distrito de Beja da sub-região do Baixo Alentejo. Envolveu alunos que frequentavam o $6 .^{\circ}, 9 .^{\circ}$ e $10 .^{\circ}$ anos de escolaridade.

A amostragem é probabilística, com amostra representativa aleatória simples (IC 95\%, $e=5 \%$ ). Foram inquiridos 36 alunos do $6 .^{\circ}$ ano, 30 alunos do $9 .^{\circ}$ ano e 72 alunos do ensino secundário.

Aplicou-se um questionário, validado previamente, no decorrer do ano letivo 2014/2015. O questionário consistiu num conjunto de questões para medir variáveis sociodemográficas e os hábitos de tabagismo dos alunos e pais e, no caso dos alunos do 3..$^{\circ} \mathrm{CEB}$ e ensino secundário, também se integraram questões para medir as opiniões dos alunos em relação ao consumo de tabaco.

As respostas ao questionário foram analisadas segundo uma abordagem quantitativa, com recurso a análises estatísticas, e os dados obtidos representados em tabelas com distribuição de frequências.

Assegurou-se que a aplicação dos questionários foi realizada de modo anónimo, sem ser possível identificar o respondente. Foi obtida autorização para realização do estudo do órgão de gestão do agrupamento de escolas e dos encarregados de educação. A base de dados encontra-se na posse do primeiro autor deste estudo. Foram cumpridos os princípios éticos para realização de estudos na área das Ciências Sociais.

\section{Resultados}

A média de idades dos alunos é, respetivamente: $6{ }^{\circ}$ ano $-11,7(\mathrm{DP}=1,37) ; 9 .^{\circ}$ ano $-14,6(\mathrm{DP}=0,64) ; 10 .^{\circ}$ ano $-16,0(\mathrm{DP}=1,15)$ anos. Cerca de $58,3 \%$ dos alunos do $6 .^{\circ}$ ano, $48,6 \%$ no $9 .^{\circ}$ ano e $45,5 \%$ no $10 .^{\circ}$ ano de escolaridade são do sexo masculino.
Na tab. 1 apresentam-se os resultados relativamente à experimentação e consumo de tabaco, sendo de seguida também apresentados os resultados relativos aos motivos desse contacto.

Tabela 1.

Experimentação e consumo de tabaco por ano de escolaridade e sexo.

\begin{tabular}{rccc}
\hline Anos & $\begin{array}{c}6 .^{\circ} \text { ano } \\
f(\%)\end{array}$ & $\begin{array}{c}9{ }^{\circ} \text { ano } \\
f(\%)\end{array}$ & $\begin{array}{c}10{ }^{\circ} \text { ano } \\
f(\%)\end{array}$ \\
\cline { 2 - 4 } Experimentou & $\mathrm{M}-7$ & $\mathrm{M}-6$ & $\mathrm{M}-18(27,3)$ \\
fumar & $(33,3)$ & $(16,2)$ & $\mathrm{F}-22(33,3)$ \\
& $\mathrm{F}-1(6,7)$ & $\mathrm{F}-7(18,9)$ & \\
& $\mathrm{M}-1$ & $\mathrm{M}-1$ & $\mathrm{M}-11(61,1)$ \\
Continua a fumar & $(14,3)$ & $(16,7)$ & $\mathrm{F}-9(40,9)$ \\
& $\mathrm{F}-0(0,0)$ & $\mathrm{F}-4(57,1)$ & \\
\hline
\end{tabular}

$\mathrm{M}$ - masculino. $\mathrm{F}$ - feminino.

Os dados da tab. 1 revelam que a experimentação ocorre em mais de $33 \%$ dos rapazes, no $6{ }^{\circ}$ ano, e que, a partir daí, são consumidores $16,7 \%-61,1 \%$ dos rapazes e $57,1 \%-40,9 \%$ das raparigas, respetivamente, no $9 .^{\circ}$ e $10 .^{\circ}$ anos de escolaridade. Cerca de $66 \%$ obteve o seu primeiro cigarro por intermédio de um/a amigo/a.

A principal razão $(91,3 \%)$ que levou estes alunos a experimentar fumar foi para ver / saber como era a sensação. Também é de registar que $27,0 \%$ dos alunos do $9 .^{\circ}$ ano e $24,2 \%$ dos do $10 .^{\circ}$ ano afirmam ser capazes de fazer coisas que os amigos pedem para não os desiludir $(44,1 \%$ dos alunos declara que mais do que três dos seus amigos fuma, valor reduzido para 33,3\% relativamente às amigas). Aliás, o melhor amigo já terá oferecido uma ou outra vez cigarros a 43,5\% dos alunos, enquanto os amigos o fizeram a mais alunos $(64,5 \%)$. Os locais de oferta são, maioritariamente, o café e a rua.

Cerca de 93\% dos alunos considera que o pai não gostaria que fumasse (96\% relativamente às mães); todavia, $17,7 \%$ considera que aceita um cigarro se um amigo lho ofertar e 13,7\% não sabe o que faria.

Somente $33 \%$ dos alunos declara que provavelmente não se tornará fumador e um grupo de $31 \%$ defende que tem certeza relativamente a abster-se deste comportamento. Note-se que $45,1 \%$ dos alunos considera que $75 \%-100 \%$ dos jovens da sua idade fumam, pelo menos, uma vez por semana, com $25,5 \%$ a defender que é apenas $50 \%-75 \%$ os que adotam este comportamento.

Tabela 2.

Prevalência de pais fumadores de alunos.

\begin{tabular}{|c|c|c|c|}
\hline \multirow[t]{3}{*}{ Anos } & $6 .^{\circ}$ ano & $9 .^{\circ}$ ano & $10 .^{\circ}$ ano \\
\hline & \multicolumn{3}{|c|}{ Fumadores } \\
\hline & $f(\%)$ & $f(\%)$ & $f(\%)$ \\
\hline Mãe & $12(33,3)$ & $9(30,0)$ & $22(30,6)$ \\
\hline Pai & $21(58,3)$ & $14(46,7)$ & $28(38,9)$ \\
\hline
\end{tabular}

Os dados da tab. 2 revelam que $30 \%$ ou mais das mães dos alunos são fumadoras e que os pais fumadores 
são-no em maior número (38,9-58,3\%); prevalências muito superiores às encontradas no estudo de Precioso, Samorinha, Araújo, Macedo e Antunes (2011) relativamente a alunos do $4 .^{\circ}$ ano de escolaridade. Tal facto constitui uma preocupação quando se considera que os pais devem ajudar na prevenção do tabagismo, quer abstendo-se de fumar na presença de crianças e jovens quer adotando uma atitude que desnormalize o ato de fumar e que não facilite o acesso ao tabaco.

Para além do modelo educacional, a situação agudiza-se relativamente ao grau de proteção da saúde da criança.

Os dados da tab. 3 deixam perceber que, no que diz respeito aos pais fumadores de alunos, fumam em casa entre $47,6 \%-50,0 \%$ dos pais, diminuindo nas mães, que se situam entre 33,3\%-46,4\%, aproximando-se aos valores encontrados pela equipa de Precioso et al. (2011), expondo as crianças ao FAT, com as consequências conhecidas da evidência científica.

Tabela 3.

Fumadores em casa.

\begin{tabular}{rccc}
\hline Anos & $6 .^{\circ}$ ano & $9 .^{\circ}$ ano & $10 .^{\circ}$ ano \\
\cline { 2 - 4 } & \multicolumn{3}{c}{ Fuma em casa } \\
\cline { 2 - 4 } Mãe & $f(\%)$ & $f(\%)$ & $f(\%)$ \\
Pai & $10(43,3)$ & $5(35,7)$ & $13(46,4)$ \\
Irmão & $0(0,0)$ & $7(50,0)$ & $14(50,0)$ \\
\hline
\end{tabular}

Os dados revelam, na continuação, uma percentagem elevada de pais e mães dos alunos do $6 .^{\circ}$ ano que nunca falaram das desvantagens de fumar: $68,8 \%$ (pais) e $42,2 \%$ (mães). Porém, os alunos do $9 .^{\circ}(86,5 \%)$ e do $10 .^{\circ}(78,8 \%)$ ano consideram importante a opinião dos pais se estes lhes dissessem que o consumo de tabaco tem malefícios na saúde e que deveriam abster-se dessa prática.

$\mathrm{Na}$ tab. 4 registam-se os resultados de seis afirmações que constavam no questionário de modo a medir a opinião dos alunos do $9 .^{\circ}$ e do $10 .^{\circ}$ anos de escolaridade sobre aspetos associados ao tabagismo.

Tabela 4.

Atitudes dos alunos relativamente ao consumo de tabaco. ${ }^{l}$

\begin{tabular}{ccccc}
\hline & \multicolumn{2}{c}{$9 .^{\circ}$ ano } & \multicolumn{2}{c}{$10 .^{\circ}$ ano } \\
\cline { 2 - 5 } Afirmações & $\mathrm{D}$ & $\mathrm{C}$ & $\mathrm{D}$ & $\mathrm{C}$ \\
& $f(\%)$ & $f(\%)$ & $f(\%)$ & $f(\%)$ \\
\hline a) & $31(86,1)$ & $1(2,8)$ & $42(67,7)$ & $10(15,2)$ \\
b) & $0(0,0)$ & $36(100)$ & $2(3,0)$ & $62(93,9)$ \\
c) & $0(0,0)$ & $34(94,4)$ & $4(6,1)$ & $54(81,8)$ \\
d) & $33(91,7)$ & $3(8,3)$ & $57(86,4)$ & $4(6,1)$ \\
e) & $31(86,1)$ & $0(0,0)$ & $49(74,2)$ & $4(6,1)$ \\
f) & $12(33,3)$ & $6(16,7)$ & $32(49,2)$ & $11(16,9)$ \\
\hline
\end{tabular}

${ }^{1} \mathrm{D}$ - discordância. C - concordância. a) Fumar só afeta a saúde das pessoas se fumarem durante muitos anos; b) Fumar prejudica a saúde dos jovens; c) Fumar em casa prejudica a saúde de quem nela habita; d) Fumar só prejudica a saúde do fumador e não a saúde das outras pessoas; e) Fumar torna as pessoas mais bonitas e interessantes; f) O fumador é um individuo com um certo estilo.

As afirmações a) e b) relacionam o consumo de tabaco e o impacto na saúde. Relativamente aos efeitos do consumo de tabaco apenas a longo prazo, no $9 .^{\circ}$ ano de escolaridade, $86,1 \%$ está de acordo com o quadro teórico; todavia, no $10 .^{\circ}$ ano, $15,2 \%$ dos alunos está em concordância com a afirmação apresentada. Sobre os efeitos do consumo de tabaco na saúde, a maioria dos alunos, de ambos os anos, considera os seus malefícios.

As afirmações c) e d) (tab. 4) permitem medir a opinião dos alunos sobre tabagismo passivo. A maioria está de acordo que fumar em casa prejudica a saúde de quem nela habita. Concordam, também, que a exposição ao FAT acarreta igualmente malefícios, do tipo dos que o fumador sofre.

Quanto ao modo como o fumador é socialmente visto - afirmações e) e f) (tab. 4) -, a maioria discorda que fumar torne as pessoas mais bonitas e interessantes. Mas, ao olharmos para o facto de o fumador ter um certo estilo, as opiniões divergem, com a maior parte dos alunos a discordar desta posição $\left(33,3 \%\right.$ no $9 .^{\circ}$ ano e $49,2 \%$ no $10 .^{\circ}$ ano).

\section{Discussão}

Os alunos mais velhos da amostra revelaram maior prevalência de consumo e experimentação do que os mais novos, tal como no estudo Health Behaviour in School Aged Children (Ferreira \& Matos, 2009) e no de Precioso et al. (2012). No entanto, a prevalência de consumo regular ao nível dos alunos do $9 .^{\circ}$ ano $(2,8 \%$ nos rapazes e $11,1 \%$ nas raparigas $)$ e do $10 .^{\circ}$ ano $(15,3 \%$ nos rapazes e $12,5 \%$ nas raparigas) enquadra-se nos valores obtidos por Precioso et al. (2012) para o contexto nacional. Note-se, porém, se levarmos em conta as percentagens dentro de cada sexo, temos consumos no $9 .^{\circ}$ ano de $5,6 \%$ entre os rapazes e de $22,2 \%$ entre as raparigas. Relativamente ao $100^{\circ}$ ano, existem $36,7 \%$ de fumadores entre os rapazes e $21,4 \%$ entre as raparigas.

No que diz respeito aos pais, os dados revelam uma maior prevalência de consumo tabágico do que a obtida por Precioso et al. (2011). As mães são menos fumadoras do que os pais em todos os anos em apreciação, embora com prevalências na ordem dos $30 \%$. Em qualquer um dos casos, a prevalência foi superior aos valores de $15,5 \%$ e $37,0 \%$ de mães e pais fumadores obtidos para pais de alunos num concelho da região norte de Portugal. Parece que existe uma tendência crescente para os pais fumarem em casa, à medida que os seus filhos vão tendo maior idade. As médias de consumos no interior da habitação crescem de $40,5 \%$, no $6 .^{\circ}$ ano, para $48,2 \%$ no $10 .^{\circ}$ ano, mas sempre inferiores à prevalência de dois terços de pais fumadores no domicílio obtidos por Precioso et al. (2011).

Pese embora uma atitude fortemente desfavorável ao hábito de fumar, pois quase todos os alunos do $9 .^{\circ}$ ano e do $10 .^{\circ}$ ano reconhecem que fumar prejudica os jovens e 
que fumar em casa prejudica a saúde de quem nela habita, cerca de $15 \%$ dos alunos do $10 .^{\circ}$ ano não discorda da afirmação que o hábito de fumar só afeta a saúde se este se mantiver por muitos anos. Quanto ao modo como o fumador é socialmente visto, realçamos a discordância acerca do tabagismo tornar as pessoas mais bonitas e interessantes. Parece, pois, que um dos mitos a trabalhar em educação para a saúde seja o facto de cerca de $17 \%$ opinar que fumar dá um certo estilo.

\section{Conclusões}

Os resultados obtidos neste estudo exploratório levam-nos a definir algumas medidas de atuação para diminuir o grau de exposição ao FAT e reduzir a prevalência do consumo de tabaco, distribuídas por três públicos-alvo:

\section{Alunos}

Com os alunos de nível de escolaridade mais baixo podem ser desenvolvidas estratégias motivadoras, como seja a participação num clube de não fumadores ou numa competição física, de modo evitar a experimentação do tabaco. A pressão dos pares, de alunos não fumadores, é importante como estratégia de prevenção relativamente ao consumo regular de tabaco.

Com os alunos de nível de escolaridade mais elevado podem ser adotadas estratégias que clarifiquem o impacto do consumo do tabaco (a curto e longo prazo) na saúde e que desmistifiquem o modo como o fumador é socialmente visto, desnormalizando o ato. Neste caso, promovendo debates, por exemplo, sobre a promoção não explícita do consumo de tabaco na televisão ou o acesso fácil a produtos de tabaco em comerciantes que não se inibem de os disponibilizarem a menores de 18 anos de idade $(45,5 \%$ dos alunos declara que compra tabaco numa tabacaria ou café).

\section{Pais e encarregados de educação}

A oferta de sessões informativas relativamente aos malefícios do tabaco (utilizando o Centro de Saúde local como parceiro) será uma estratégia a considerar a curto prazo. Tendo em consideração esse conhecimento, os pais e os encarregados de educação podem ser sensibilizados para a importância do seu papel na continuidade das ações de prevenção da experimentação e do consumo regular que a escola desenvolve. Considera-se decisivo, também, que os pais e encarregados de educação se abstenham de fumar (para tal, o Centro de Saúde pode realizar abordagens breves de cessação tabágica) ou, estando num estado de pré-contemplação, que sejam sensibilizados para a cessação tabágica e que se inibam de fumar no interior da sua residência e do seu veículo automóvel, protegendo os seus educandos do FAT.

\section{Trabalhadores docentes e não docentes}

Estes profissionais da educação, em exercício, constituem modelos para os alunos. $\mathrm{O}$ agrupamento de escolas pode, em articulação com o Centro de Saúde, promover abordagens breves de cessação tabágica. Aqueles que estiverem num estado de pré-contemplação devem evitar fumar à vista dos alunos e ser sensibilizados para a cessação tabágica.

\section{Referências bibliográficas}

Alves, J., Kunst, A. , \& Perelman, J. (2015). Evolution of socioeconomic inequalities in smoking: results from the Portuguese national health interview surveys. BMC Public Health, 15, 311-318.

Constituição da República Portuguesa. Disponível em: https://www.parlamento.pt/ArquivoDocumentacao/Do cuments/CRPVIIrevisao.pdf.

Convenção sobre os Direitos da Criança. Disponível em:

https://www.unicef.pt/docs/pdf_publicacoes/convenca o_direitos_crianca2004.pdf.

Cristina, A., Alves, J., \& Perelman, J. (2015) Desigualdades socioeconómicas no tabagismo em jovens dos 15 aos 17 anos. Revista Portuguesa de Saúde Pública, 34(1), 69-76. Disponível em: http://www.sciencedirect.com/science/article/pii/S087 0902515000607.

EPA US Environmental Protection Agengy (2016). Secondhand Tobacco Smoke and Smoke-free Homes. Disponível em: https://www.epa.gov/indoor-air-quality-iaq/secondhan d-tobacco-smoke-and-smoke-free-homes.

Ferreira, M., \& Matos, M. (2009). O consumo de substâncias. In Matos, M., \& Sampaio, D. (Coord.). Jovens com saúde. Diálogo com uma geração (pp. 91-96). Lisboa: Texto Editores.

Kuipers M., de Korte, R., Soto, V., Richter, M., Moor, I., Rimpela, A., et al. (2015). School smoking policies and educational inequalities in smoking behaviour of adolescents aged 14-17 years in Europe. J. Epidemiol Community Health, 70(2), 132-139. Disponível em: http://jech.bmj.com/content/70/2/132.share.

Nunes, E. (2007). Tabaco e saúde. In Pestana, E. (Coord.). Tabagismo, do diagnóstico ao tratamento. (pp. 243-260). Lisboa: Lidel.

Pestana, E. (2010). Tabagismo passivo. In Baptista, M., \& Sousa, A. (Coord.). Consumo de substâncias psicoativas e prevenção em meio escolar (pp. 19-37). Lisboa: DGIDC do Ministério da Educação.

Precioso, J., Samorinha, C., Araújo, C., Macedo, M., \& Antunes, H. (2011). Exposición de niños al humo ambiental del tabaco (FAT): un estúdio efectuado con alunos de $4 .^{\circ}$ curso de escolaridade de Braga Portugal. Prevención del tabaquismo, 13(3), 112-116.

Precioso, J., Samorinha, C., Macedo, M., \& Antunes, H. (2012). Prevalência do consumo de tabaco em adolescentes escolarizados portugueses por sexo: podemos estar otimistas? Revista Portuguesa de Pneumologia, 18(4), 182-187.

\section{Agradecimentos}

Os autores agradecem aos alunos que contribuíram com a sua boa vontade na resposta ao questionário. 